\title{
Cyclin A and cyclin DI as significant prognostic markers in colorectal cancer patients
}

\author{
Abeer A Bahnassy*1, Abdel-Rahman N Zekri ${ }^{2}$, Soumaya El-Houssini ${ }^{1}$, \\ Amal MR El-Shehaby ${ }^{3}$, Moustafa Raafat Mahmoud ${ }^{1}$, Samira Abdallah ${ }^{4}$ and \\ Mostafa El-Serafi ${ }^{5}$
}

\begin{abstract}
Address: ${ }^{1}$ Pathology Department, National Cancer Institute, Cairo University, Cairo, Egypt, ${ }^{2}$ Virology and Immunology Unit, Cancer Biology Department, National Cancer Institute, Cairo University, Cairo, Egypt, ${ }^{3}$ Biochemistry Department, Kasr El-Eini School of Medicine, Cairo University, Cairo, Egypt, ${ }^{4}$ Pathologyy Department, Kasr El-Eini School of Medicine, Cairo University, Cairo, Egypt and ${ }^{5}$ Medical Oncology Department, National Cancer Institute, Cairo University, Cairo, Egypt

Email: Abeer A Bahnassy* - chaya2000@hotmail.com; Abdel-Rahman N Zekri - ncizakri@starnet.com.eg; Soumaya ElHoussini - chaya2000@hotmail.com; Amal MR El-Shehaby - chaya2000@hotmail.com; Moustafa Raafat Mahmoud - ncizakri@starnet.com.eg Samira Abdallah - chaya2000@hotmail.com; Mostafa El-Serafi - melserafi@starnet.com.eg

* Corresponding author
\end{abstract}

Published: 23 September 2004

BMC Gastroenterology 2004, 4:22 doi:10.1 186/I47/-230X-4-22
Received: 25 April 2004

Accepted: 23 September 2004

This article is available from: http://www.biomedcentral.com/I47I-230X/4/22

(C) 2004 Bahnassy et al; licensee BioMed Central Ltd.

This is an open-access article distributed under the terms of the Creative Commons Attribution License (http://creativecommons.org/licenses/by/2.0), which permits unrestricted use, distribution, and reproduction in any medium, provided the original work is properly cited.

\begin{abstract}
Background: Colorectal cancer is a common cancer all over the world. Aberrations in the cell cycle checkpoints have been shown to be of prognostic significance in colorectal cancer.

Methods: The expression of cyclin DI, cyclin A, histone $\mathrm{H} 3$ and $\mathrm{Ki}-67$ was examined in 60 colorectal cancer cases for co-regulation and impact on overall survival using immunohistochemistry, southern blot and in situ hybridization techniques. Immunoreactivity was evaluated semi quantitatively by determining the staining index of the studied proteins.

Results: There was a significant correlation between cyclin $D /$ gene amplification and protein overexpression (concordance $=63.6 \%$ ) and between $\mathrm{Ki}-67$ and the other studied proteins. The staining index for Ki-67, cyclin $A$ and $D I$ was higher in large, poorly differentiated tumors. The staining index of cyclin $D I$ was significantly higher in cases with deeply invasive tumors and nodal metastasis. Overexpression of cyclin $A$ and $D I$ and amplification of cyclin $D /$ were associated with reduced overall survival. Multivariate analysis shows that cyclin DI and $A$ are two independent prognostic factors in colorectal cancer patients.

Conclusions: Loss of cell cycle checkpoints control is common in colorectal cancer. Cyclin A and $D /$ are superior independent indicators of poor prognosis in colorectal cancer patients. Therefore, they may help in predicting the clinical outcome of those patients on an individual basis and could be considered important therapeutic targets.
\end{abstract}

\section{Background}

Colorectal cancer (CRC) is the third most common cancer in Western countries [1]. In Egypt, CRC has unique char- acteristics that differ from that reported in other countries of the western society. It was estimated that $35.6 \%$ of the Egyptian CRC cases are below 40 years of age and patients 
usually present with advanced stage, high grade tumors that carry more mutations [2]. This uniquely high proportion of early-onset CRC, the early and continuous exposure to hazardous environmental agents, the different mutational spectrum and the prevalent consanguinity in Egypt justify further studies [3]. It was proved that most cancers result from accumulation of genetic alterations involving certain groups of genes, the majority of which are cell cycle regulators that either stimulate or inhibit cell cycle progression [1]. Cell proliferation allows orderly progression through the cell cycle, which is governed by a number of proteins including cyclins and cyclin dependent kinases $[4,5]$. The cyclins belong to a superfamily of genes whose products complex with various cyclin-dependent kinases ( $c d k s)$ to regulate transitions through key checkpoints of the cell cycle [6]. Abnormalities of several cyclins have been reported in different tumor types, implicating, in particular, cyclin A, cyclin E and cyclin D [6,7].

Cyclin D1 is a G1 cyclin that regulates the transition from G1 to S phase since its peak level and maximum activity are reached during the $\mathrm{G} 1$ phase of the cell cycle. Whereas cyclin $A$ is regarded a regulator of the transition to mitosis since it reaches its maximum level during the $S$ and G2 phases [8]. The mechanisms likely to activate the oncogenic properties of the cyclins include chromosomal translocations, gene amplification and aberrant protein overexpression $[7,9]$.

Several studies have shown that, histone H3 mRNA expression can be used to identify the S phase fraction (SPF) through the in situ hybridization (ISH) technique $[10,11]$. The level of histone $\mathrm{H} 3$ mRNA reaches its peak during the $S$ phase and then drops rapidly at the G2 phase [12].

In face of the increasing incidence of CRC and its peculiar pattern in the Egyptian population, the present study was conducted to assess the role of Ki-67 (pan-cell cycle marker), cyclin D1 (G1 phase marker), histone H3 mRNA (S phase marker), cyclin A (S to G2 phase marker) in CRC. The expression level of these markers was correlated to the clinicopathologic features and the overall survival of patients.

Table I: Clinicopathological features of patients in relation to the staining index (SI) of Ki-67, cyclin DI, cyclin A, histone $\mathrm{H3}$

\begin{tabular}{|c|c|c|c|c|c|}
\hline \multirow[b]{2}{*}{ Variables } & \multirow[b]{2}{*}{ No. of cases } & \multicolumn{4}{|c|}{$S I$ (mean + SD) } \\
\hline & & $K i-67$ & Cyclin DI & Cyclin A & Histone $\mathrm{H3}$ \\
\hline \multicolumn{6}{|l|}{ Sex } \\
\hline Male & 36 & $18.0 \pm 6.4$ & $6.7 \pm 4.3$ & $12.7 \pm 5.7$ & $10.7 \pm 5.3$ \\
\hline Female & 24 & $20.1 \pm 5.8$ & $8.8 \pm 8.4$ & $10.0 \pm 6.0$ & $10.7 \pm 5.4$ \\
\hline \multicolumn{6}{|l|}{ Age (years) } \\
\hline$\geq \mathbf{5 0}$ & 41 & $11.7 \pm 6.0 *$ & $5.6 \pm 5.2$ & $10.0 \pm 5.3$ & $6.0 \pm 5.0^{*}$ \\
\hline$<50$ & 19 & $23.8 \pm 5.6$ & $7.7 \pm 6.8$ & $13.6 \pm 5.7$ & $22.0 \pm 5.2$ \\
\hline \multicolumn{6}{|l|}{ Tumor size $(\mathrm{cm})$} \\
\hline$<5.0$ & 33 & $12.2 \pm 6.3^{*}$ & $5.3 \pm 3.8^{*}$ & $11.5 \pm 6.1^{*}$ & $10.3 \pm 4.9 *$ \\
\hline$\geq 5.0$ & 27 & $30.1 \pm 6.2$ & $22.8 \pm 7.2$ & $28.6 \pm 5.6$ & $24.0 \pm 5.6$ \\
\hline \multicolumn{6}{|l|}{ Histology } \\
\hline Normal & 20 & $3.5 \pm 2.0^{*}$ & $0.6 \pm 0.2^{*}$ & $2.3 \pm 1 . I^{*}$ & $2.2 \pm 0.9$ \\
\hline Carcinoma & 60 & $30.3 \pm 6.2$ & $24.9 \pm 6.3$ & $27.2 \pm 5.8$ & $10.7 \pm 5.3$ \\
\hline GI & 15 & $11.7 \pm 6.2$ & $6.6 \pm 4.0$ & $10.0 \pm 5.4$ & $11.4 \pm 4.9$ \\
\hline GII & 21 & $11.8 \pm 5.6$ & $8.9 \pm 3.6$ & $12.3 \pm 6.5$ & $7.8 \pm 5.4$ \\
\hline GIII & 24 & $30.0 \pm 4.3$ & $22.0 \pm 8.1$ & $27.0 \pm 4.9$ & $11.5 \pm 5.4$ \\
\hline \multicolumn{6}{|l|}{ Lymph node } \\
\hline Negative & 33 & $19.5 \pm 7.0$ & $5.4 \pm 5.3^{*}$ & $11.9 \pm 6.5$ & $12.3 \pm 5.5$ \\
\hline Positive & 27 & $21.3 \pm 4.9$ & $20.6 \pm 6.9$ & $12.5 \pm 5.0$ & $14.2 \pm 5.0$ \\
\hline \multicolumn{6}{|c|}{ Depth of invasion } \\
\hline$m, s m$ & 17 & $20.7 \pm 6.7$ & $3.1 \pm 3.1 *$ & $11.9 \pm 7.2$ & $10.4 \pm 5.1$ \\
\hline beyond sm & 43 & $21.9 \pm 6.2$ & $12.4 \pm 6.5$ & $12.2 \pm 5.6$ & $10.7 \pm 5.4$ \\
\hline \multicolumn{6}{|l|}{ Stage } \\
\hline$i$ & 6 & $20.6 \pm 6.7$ & $5.7 \pm 6.9$ & $24.2 \pm 6.9$ & $\mathrm{II} . \mathrm{I} \pm 5.3$ \\
\hline II & 27 & $20.8 \pm 6.9$ & $5.3 \pm 4.3$ & $24.6 \pm 6.0$ & $10.4 \pm 5.7$ \\
\hline III & 12 & $22.0 \pm 5.4$ & $7.7 \pm 6.0$ & $27.1 \pm 5.2$ & $10.4 \pm 4.9$ \\
\hline IV & 15 & $24.7 \pm 6.1$ & $11.3 \pm 9.6$ & $27.5 \pm 5.5$ & $12.3 \pm 6.2$ \\
\hline
\end{tabular}

\footnotetext{
$*$ p. value $<0.05$ (significant)
} 


\section{Methods}

\section{Tissue samples}

Paraffin-embedded tumor tissues were obtained from 60 CRC patients (47 colon and 13 rectal carcinomas) that were diagnosed and treated at the National Cancer Institute, Cairo, Egypt during the period from January, 1997 to June, 2002. Clinicopathological data of the studied cases are illustrated in table 1 . None of the patients received any chemotherapy or irradiation prior to surgery. Histological diagnosis of all cases was done by 2 independent pathologists according to the WHO Histological Classification. Tumors were staged according to the TNM staging system [13]. The depth of tumor invasion was classified as invasion of the mucosa including muscularis mucosa (m), invasion of the submucosa (sm), or invasion beyond the submucosa [8]. Normal colonic tissues were obtained from autopsy specimens $(n=20)$ and were used as a control. The actual survival rate of the patients was calculated from the date of resection to the date of death.

\section{Immunohistochemistry}

Four micron sections of each normal and tumor specimen were cut onto positive-charged slides; air dried overnight, de-paraffinized in xylene, hydrated through a series of graded alcohol and washed in distilled water and 0.01 PBS (pH 7.4). Slides were then processed for IHC as described by Handa et al. [8]. using the following antibodies: Ki-67 (MIB-1, Dako), cyclin A (6E6; Novocastra, Newcastle-Upon-Tyne, UK) and cyclin D1 (DCS-6, Dako). A case of invasive breast cancer was used as a positive control for Ki-67 and cyclin A whereas a case of mantle cell lymphoma was used as a control for cyclin D1. Negative controls were obtained by replacing the primary antibody by non-immunized rabbit or mouse serum.

Brown nuclear staining was regarded as a positive result for all studied markers. The proportion of positivelystained cells and the intensity of staining were scored in tumor and normal colorectal mucosal sections at medium power $(\times 200)$. The degree of positive tumor staining (percentage of positive tumor cells in the examined section) was scored from 1-6 and the staining intensity was scored from 0-6 according to the pattern of staining in the examined section. Staining index (SI) was calculated by multiplying the cellularity and staining scores as described by King et al. [14].

\section{In situ hybridization}

All tumor samples and 5 normal controls were assessed for histone H3 mRNA by ISH using the commercially available 550 base fluorescein-labeled DNA probe (Dako, Carpinteria, CA) as described by Nagao et al., 1996. This probe hybridizes to the whole mRNA transcript of the human histoneH3 gene including the5' and 3' un-translated regions. Scoring of histone $\mathrm{H} 3 \mathrm{mRNA}$ was performed as for immunohistochemistry, however, hybridization signals were detected in the cytoplasm.

\section{Molecular detection of cyclin DI gene amplification}

High molecular weight DNA was extracted from paraffinembedded tissues of the tumor and normal colorectal mucosal samples as previously described [15]. The proportion of neoplastic and normal cells was determined in each tumor sample by examining hematoxylin and eosinstained slides obtained from the edge of the specimen used for DNA extraction. Tumor samples were evaluated for amplification of cyclin D1 if more than $75 \%$ of the examined sections were formed of neoplastic cells. Accordingly, 50 cases were eligible for the analysis. Ten micrograms of the extracted DNA was digested with EcoR1. DNA from selected cases was also digested with BglII and HindIII. Samples were separated on $0.8 \%$ agarose gels and transferred to Hybond-N membranes (Amersham Int., Amersham, UK). The membranes were hybridized with $50 \%$ formamide, $5 \times$ SSC, $5 \times$ Denhardt's, $500 \mu \mathrm{g} / \mathrm{ml}$ denatured salmon sperm DNA, 10\% dextran sulphate and $10^{6} \mathrm{cpm} / \mathrm{ml}$ of 32 P-labeled PRAD-1 probe for $24 \mathrm{~h}$. Membranes were washed with $2 \times$ SSC, $0.1 \%$ SDS at room temperature for $30 \mathrm{~min}$ followed by $2 \times \mathrm{SSC}, 0.1 \%$ SDS at $60^{\circ} \mathrm{C}$ for $30 \mathrm{~min}$ and $0.1 \times \mathrm{SSC}, 0.1 \%$ SDS at $60^{\circ} \mathrm{C}$ for $1 \mathrm{~h}$. Filters were autoradiographed using an intensifying screen at $-70^{\circ} \mathrm{C}$ for $24-72 \mathrm{~h}$. After being stripped free of the PRAD-1 probe, the same blots were hybridized with ${ }^{32} \mathrm{P}$-labeled B-actin probe to normalize against possible variations in the loading or transfer of DNA. The autoradiograms were analyzed using a densitometer. Intensities of PRAD-1/cyclin D1 were normalized to the $\beta$-actin control bands. The degree of amplification was calculated from these normalized values. Amplification was considered when the signal of the tumor band was $\geq 2$-fold the value of the matched normal mucosa [16].

\section{Statistical analysis}

The Mann-Whitney non-parametric test was used to compare the SIs of pairs of subjects whereas the Kruskal-wallis was used for categorial data. Correlation between indices was performed using a simple linear regression test. The Kaplan-Meier method was used to create survival curves which were analyzed by the log-rank test. The impact of different variables on survival was determined using the Cox proportional hazards model. $p$. values less than 0.05 were considered significant.

\section{Results}

The results of IHC are illustrated in figures 1 and 2. In general, the staining index (SIs) of all studied markers was higher in carcinomas than in normal colonic mucosal samples $(p=0.0001)$. Normal colorectal mucosa revealed positive imunostaining for Ki-67 in the lower half of the crypts only. A heterogeneous staining pattern was 


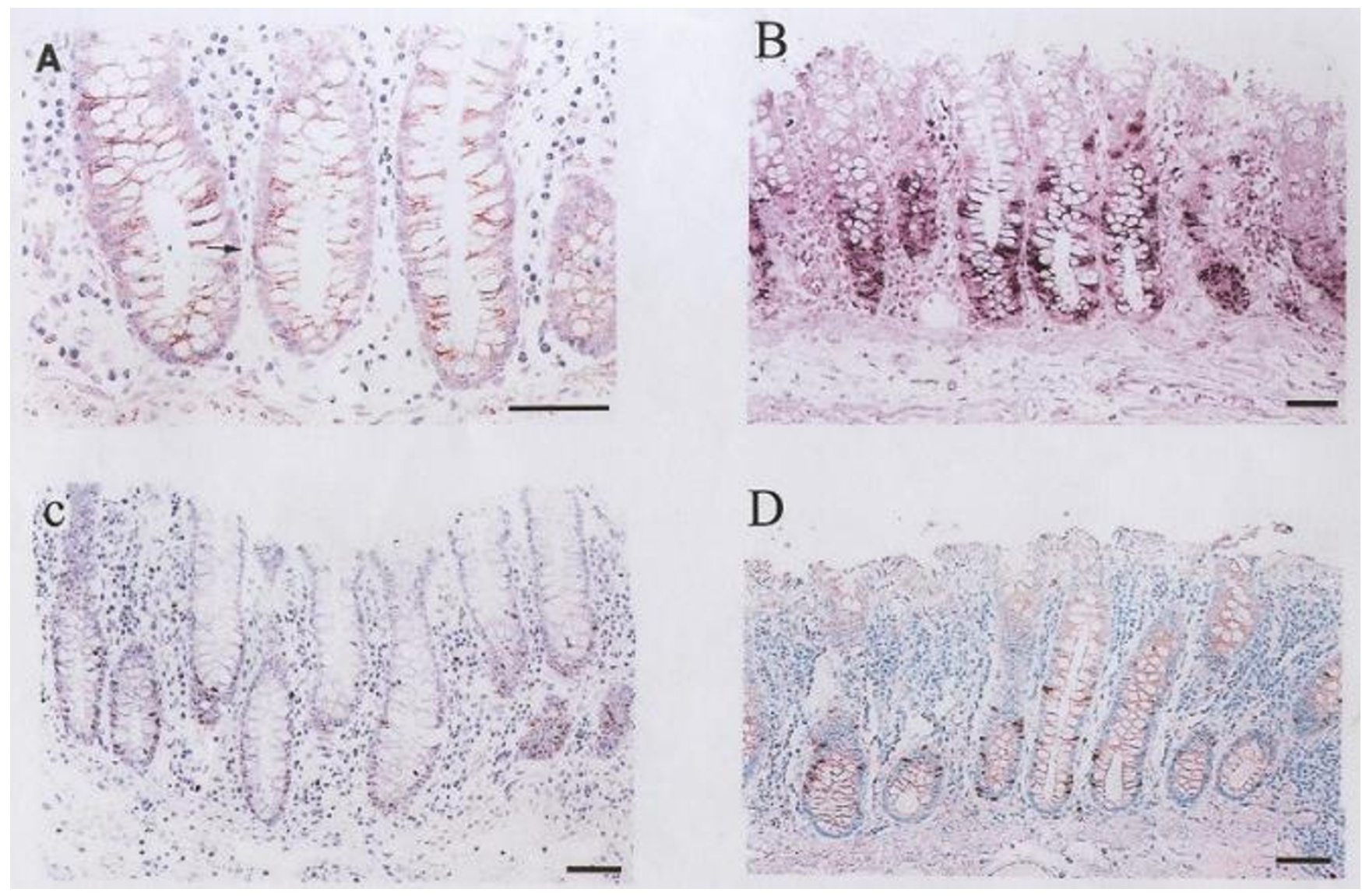

Figure I

Normal colonic mucosa showing positive nuclear immunostaining for: (a) cyclin DI, (b) ISH of histone H3 mRNA, (c) Ki-67 and (d) cyclin A

detected in the neoplastic cells of well and moderately-differentiated adenocarcinomas whereas a diffuse homogeneous staining pattern was detected in poorlydifferentiated carcinomas. The SI ranged from 10-40.2 (mean: $24.6 \pm 6.5$ ).

Immunostaining for cyclin D1 was predominantly nuclear but cytoplasmic staining was detected in some cases. However, unless a nuclear staining was also detected, cases with cytoplasmic staining were considered negative. Normal colorectal mucosal samples were almost negative for cyclin D1 whereas 41 out of the 60 (68.3\%) CRC cases were positive. Marked heterogeneity was observed in welland moderately-differentiated adenocarcinomas even within the same tumor. Poorly-differentiated carcinomas revealed a diffuse staining pattern with more darklystained nuclei. The SI ranged from 0.5-28.6 (mean: $9.3 \pm$ 4.2).
Positive nuclear staining for cyclin A was detected in $80 \%$ $(48 / 60)$ of CRC cases and in all non-neoplastic control samples. Positively-stained nuclei were confined to the lower half of the crypts in normal colonic mucosa and diffusely-dispersed in carcinomas. The SI ranged from 3.330.2 (mean: $15.1 \pm 6.6$ ).

Histone H3 mRNA was intensely expressed in the cytoplasm of all examined samples either neoplastic or nonneoplastic. The distribution of histone H3 mRNA was similar to that of cyclin A and Ki-67 however, the proportion of histone $H 3$ mRNA positive cells was less than that of Ki-67. The SI ranged from 1.8-24.2 (mean: $12.4 \pm 5.3$ ).

The PRAD-1 probe detected 3 EcoRI fragments of 4.0, 2.2 and 2.0 and $1 B g l \mathrm{II}$ fragment of $15 \mathrm{~Kb}$. PRAD-1/cyclin D1 gene amplification was detected in 22/50 (44\%) cases analyzed. The degree of amplification was heterogeneous 

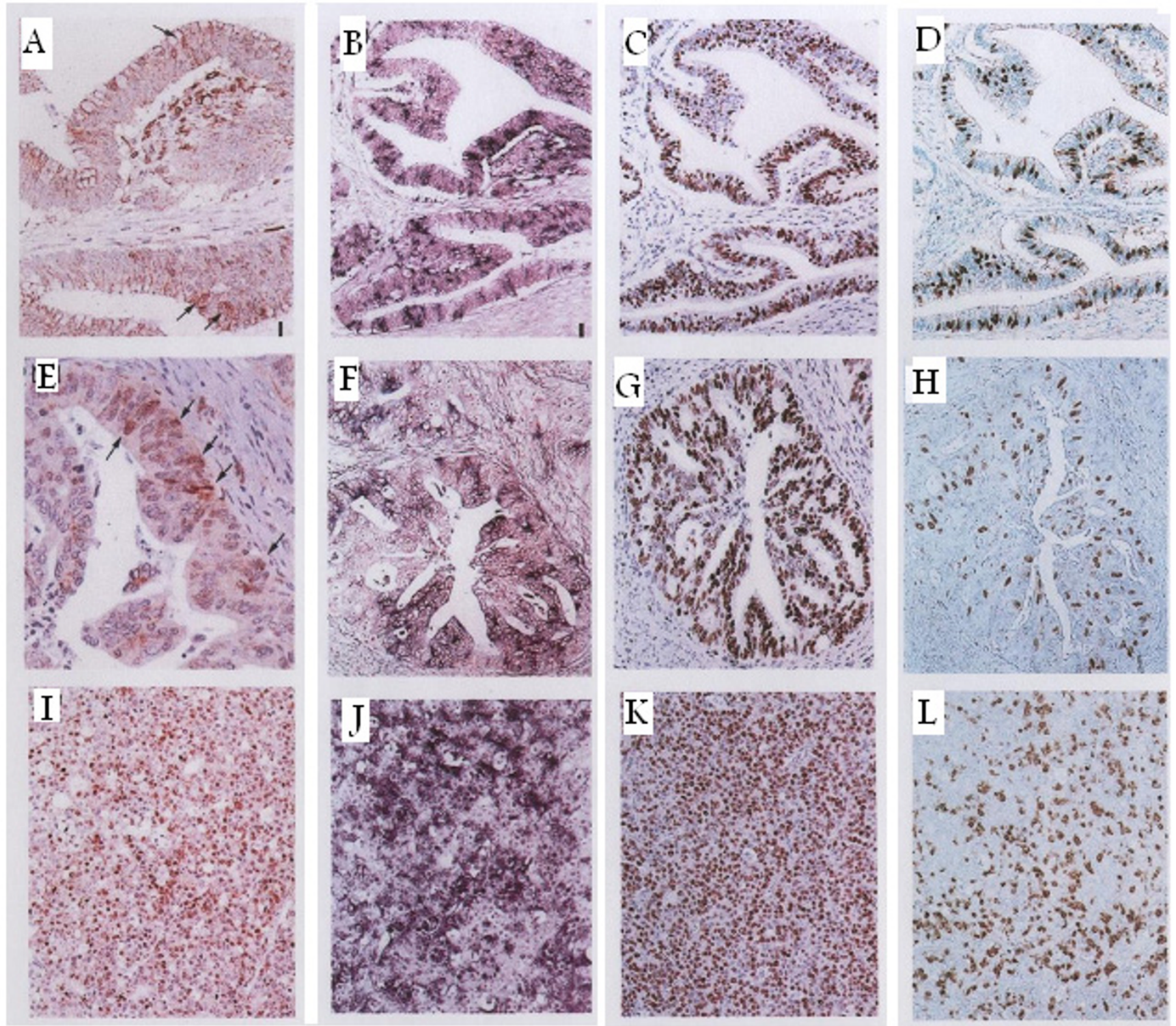

\section{Figure 2}

A case of well differentiated adenocarcinoma with positive immunostaining for: (a) cyclin DI, (b) histone H3 mRNA, (c) Ki-67, and (d) cyclin A. Another case of moderately differentiated denocarcinoma with positive immunostaining for: (e) cyclin DI, (f) histone H3 mRNA, (g) Ki-67, and (h) cyclin A. A case of poorly differentiated adenocarcinoma with diffuse staining for: (i) cyclin $\mathrm{DI}$, (j) ISH of histone $\mathrm{H} 3$ mRNA, (k) Ki-67 and (I) cyclin A.

with 2-10 fold increase when compared to normal mucosal samples (Figure 3). Amplification was confirmed by other restriction enzymes.

\section{Correlations}

There was a significant correlation between cyclin D1 gene amplification and protein overexpression. Out of the 22 cases that showed amplification 14 showed protein overexpression (concordance $=63.6 \%$ ).

Linear regression analysis of SIs revealed a significant correlation between Ki-67 and cyclin D1, cyclin A, histone H3 as well as between the SIs of cyclin $A$ and histone H3 ( $p=$ $0.008,0.0001$, and 0.0001 respectively) (Figure 4 ). There was a significant relationship between the SI of both Ki-67 
A

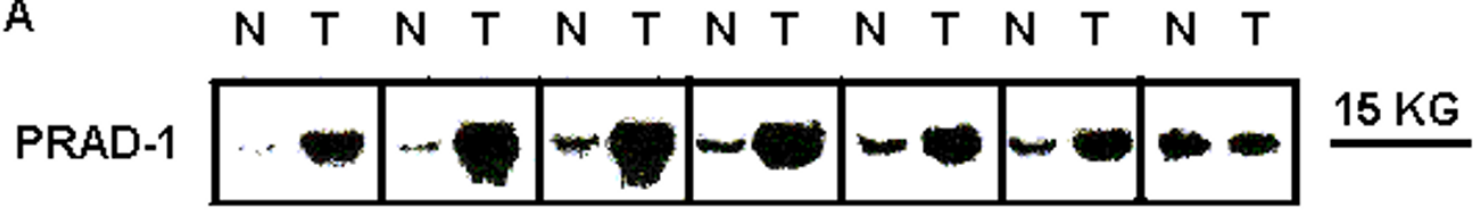

B-Actin

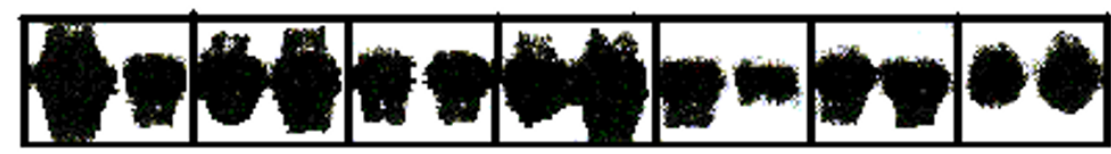

B

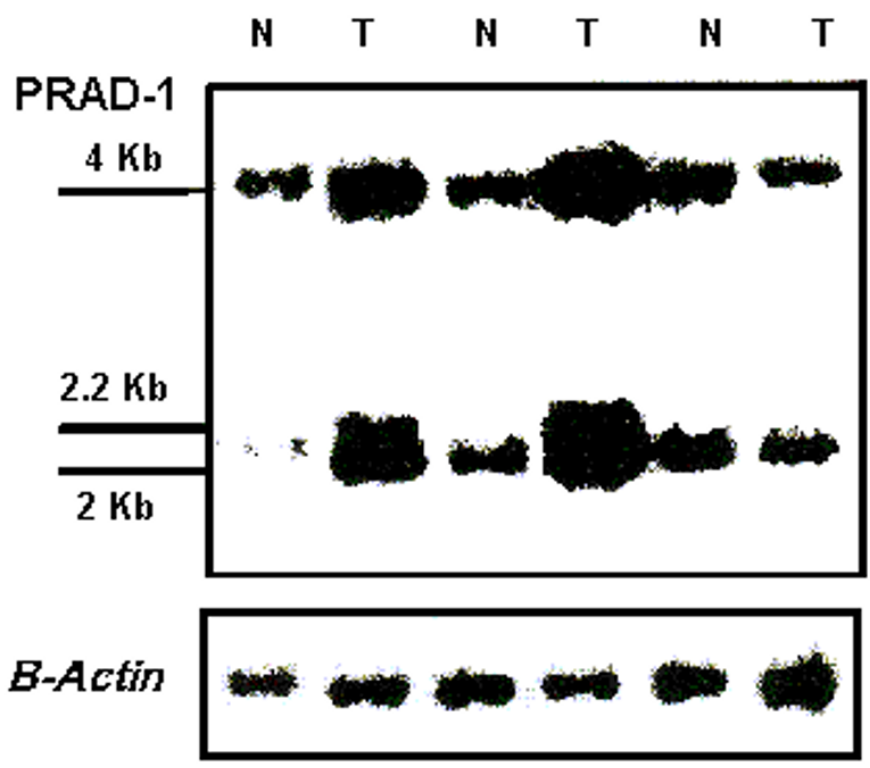

Figure 3

A: Southern blot analysis of normal mucosa $(\mathrm{N})$ and their seven corresponding cases of colonic adenocarcinomas (TI-T7), cases No. I, 2, 4, and 5 are poorly differentiated whereas cases No. 3, 6, and 7 are moderately differentiated. Genomic DNA was digested with BgIll, fractionated by electrophoresis in agarose gel, transferred onto membranes and hybridized with PRADI and $\beta$-actin. Tumors number I-6 (Lanes I-6) show different degrees of PRAD / /cyclin D I amplification, tumor number 7 (lane 7 ) was not amplified. B: Southern blot analysis of 3 cases of adenocarcinomas ( $T$ ) and matched normal colonic mucosa ( $N$ ). Genomic DNA was digested with EcoRI, fractionated by electrophoresis in agarose gel, transferred onto membranes and hybridized with PRADI and $\beta$-actin probes for loading control. The identification of the 3 tumors is the same as in Fig. $3 A$ with amplification of PRAD I/cyclin DI in tumors number 4, 5 (Lanes I, 2) but not 7 (Lane 3).

and cyclin $A$ and the degree of differentiation of tumors as well as the size of the tumor $(p<0.001$ and $p<0.01$ respectively). In addition, SI of Ki-67 and histone $\mathrm{H3}$ were higher in patients $<50$ years than in those $\geq 50$ years $(p<$ 0.05) (table 1).
In addition table 2 shows a significant relationship between high cyclin D1 SI and large, poorly-differentiated tumors, carcinomas with positive lymph node metastasis and deeply-invasive carcinomas $(p<0.05, p<0.001, p<$ 0.05 and $p<0.05$ respectively). Whereas cyclin D1 gene amplification was significantly associated with an advanced disease stage since amplification was detected in 

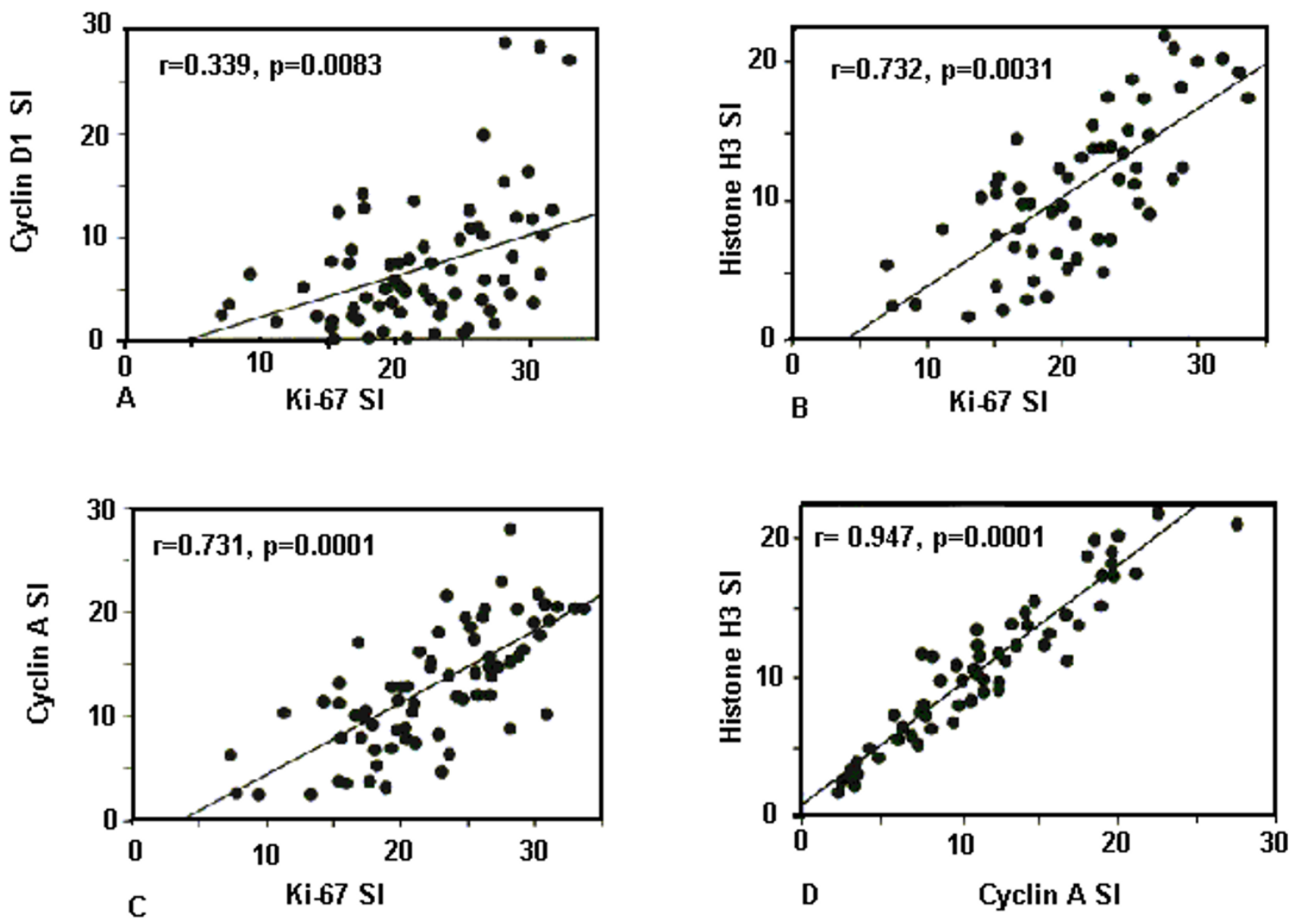

Figure 4

Correlation between the staining intensity of (a) Ki-67 vs. cyclin DI, (b) Ki-67 vs. histone H3, (c) Ki-67 vs. cyclin A and (d) cyclin A vs. histone $\mathrm{H} 3$ mRNA expression.

$10 / 15(66.7 \%)$ of stage IV tumors compared to $12 / 45$ $(26.7 \%)$ of stage I-III tumors $(p=0.002)$. Similarly, DNA amplification was detected in $60.5 \%$ (26/43) of the carcinomas with extensive local invasion (beyond $\mathrm{sm}$ ) but only in $23.5 \%$ (4/17) of the carcinomas with limited invasion $(\mathrm{m}, \mathrm{sm})(p=0.001)$. A significant correlation was also present between cyclin D1 gene amplification and the presence of lymph node metastasis $(p=0.008)$ as well as between the SI of histone $\mathrm{H3}$, the size of the tumor and the patient's age ( $p<0.05, p<0.001$ respectively). The SI was higher in tumors $>5 \mathrm{~cm}$ in diameter and in patients $<50$ years.

\section{Survival analysis}

The mean follow-up period for all patients was 30 months (range: 1-66 months). Eighteen of 60 patients had already died by the time the study was completed. We defined the cutoff level for overexpression of each cell cycle marker at the point that showed the maximum difference of survival rate between the 2 groups separated by that point. Cox regression analysis revealed that cyclin $A$ overexpression (our definition: SI $\geq 10.5$ ), cyclin D1 overexpression (our definition: $\mathrm{SI} \geq 6.1$ ), poorly differentiated histology, lymph node metastasis, TNM stage, tumor size and depth of invasion were all significant prognostic variables for survival (Table 3). The Kaplan-Meier survival curves for the subgroups of patients who are subdivided according to each marker's status are shown in Figure 5. Patient with tumors that showed $K i-67$ overexpression (our definition: $\mathrm{SI} \geq 11.5$ ) and histone $H 3$ overexpression (our definition: $\mathrm{SI} \geq 8.2$ ) tended to have poor prognosis but this did not reach a statistically significant level, however the overall survival was significantly lower in patient with cyclin A and cyclin D1 overexpression. Cox multivari- 
Table 2: The relation between cyclin DI overexpression vs cyclin DI amplification and clinicopathological prognostic markers.

\begin{tabular}{|c|c|c|c|}
\hline Variables & No. of cases & Cyclin DI overexpression & Cyclin DI Amplification \\
\hline \multicolumn{4}{|c|}{ Tumor size $(\mathrm{cm})$} \\
\hline$<5.0$ & 33 & $5.3 \pm 3.8^{*}$ & $13 / 33$ \\
\hline$\geq 5.0$ & 27 & $22.8 \pm 7.2 p<0.05$ & $9 / 27 p<0.236$ \\
\hline \multicolumn{4}{|l|}{ Histology } \\
\hline GI & 15 & $6.6 \pm 4.0$ & $7 / 15$ \\
\hline GII & 21 & $8.9 \pm 3.6$ & $8 / 21$ \\
\hline GIII & 24 & $22.0 \pm 8.1 p<0.001$ & $7 / 24 p<0.075$ \\
\hline \multicolumn{4}{|l|}{ Lymph node } \\
\hline Negative & 33 & $5.4 \pm 5.3^{*}$ & 6/33 (18.2\%) \\
\hline Positive & 27 & $20.6 \pm 6.9 p<0.05$ & $16 / 27(59.3 \%) p<0.008$ \\
\hline \multicolumn{4}{|c|}{ Depth of invasion } \\
\hline$m, s m$ & 17 & $3.1 \pm 3.1^{*}$ & $4 / 17$ (23.5\%) \\
\hline beyond sm & 43 & $12.4 \pm 6.5 p<0.05$ & $26 / 43(60.5 \%) p<0.001$ \\
\hline \multicolumn{4}{|l|}{ Stage } \\
\hline early & 45 & $5.5 \pm 10.1$ & I2/45 (26.7\%) \\
\hline late & 15 & $11.3 \pm 9.6 P=0.175$ & $10 / 15(66.7 \%) p<0.002$ \\
\hline
\end{tabular}

Table 3: Uunivariate analysis of the relationship between survival and the tested markers

\begin{tabular}{|c|c|c|c|c|}
\hline PredictiveVariables & Median Survival & $H R$ & $\mathrm{Cl}$ & $P$ \\
\hline \multicolumn{5}{|l|}{$K i-67$} \\
\hline$<11.5$ & 36 & & & \\
\hline$\geq 11.5$ & 32 & 1.826 & $0.636-5.243$ & 0.26 \\
\hline \multicolumn{5}{|l|}{ Cyclin DI } \\
\hline$<6.1$ & 35 & & & \\
\hline$\geq 6.1$ & 18 & 7.246 & $1.007-45.150$ & $0.03^{*}$ \\
\hline \multicolumn{5}{|l|}{ Histone $\mathrm{H} 3$} \\
\hline$<8.2$ & 35 & & & \\
\hline$\geq 8.2$ & 29 & 4.639 & $0.854-25.196$ & 0.07 \\
\hline \multicolumn{5}{|l|}{ Cyclin A } \\
\hline$<10.5$ & 35 & & & \\
\hline$\geq 10.5$ & 15 & 7.820 & $1.017-60.122$ & $0.02 *$ \\
\hline \multicolumn{5}{|l|}{ Histological grade } \\
\hline Low & 38 & & & \\
\hline High & 10 & 7.331 & $2.696-19.940$ & $0.0001 *$ \\
\hline \multicolumn{5}{|l|}{ Lymph node } \\
\hline Negative & 38 & & & \\
\hline Positive & 15 & 6.826 & $1.973-23.621$ & $0.002 *$ \\
\hline \multicolumn{5}{|l|}{ Stage } \\
\hline I, II, III & 38 & & & \\
\hline IV & 12 & 6.378 & $1.842-22.083$ & $0.001 *$ \\
\hline \multicolumn{5}{|l|}{ Tumor size $(\mathrm{cm})$} \\
\hline$<5.0$ & 35 & & & \\
\hline$\geq 5.0$ & 13 & 4.835 & $1.386-16.868$ & $0.01 *$ \\
\hline \multicolumn{5}{|l|}{ Depth of invasion } \\
\hline TI, T2 & 36 & & & \\
\hline $\mathrm{T} 3, \mathrm{~T} 4$ & 20 & 7.759 & $1.024-58.789$ & $0.04^{*}$ \\
\hline \multicolumn{5}{|l|}{ Age (years) } \\
\hline$<50$ & 38 & & & \\
\hline$\geq 50$ & 28 & 2.802 & $0.988-7.943$ & 0.0526 \\
\hline \multicolumn{5}{|l|}{ Sex } \\
\hline Male & 38 & & & \\
\hline Female & 36 & 0.696 & $00.274-1.766$ & 0.4449 \\
\hline
\end{tabular}

* p. value $<0.05$ (significant) HR: Hazard Ratio

$\mathrm{Cl}: 95 \%$ confidence Interval 

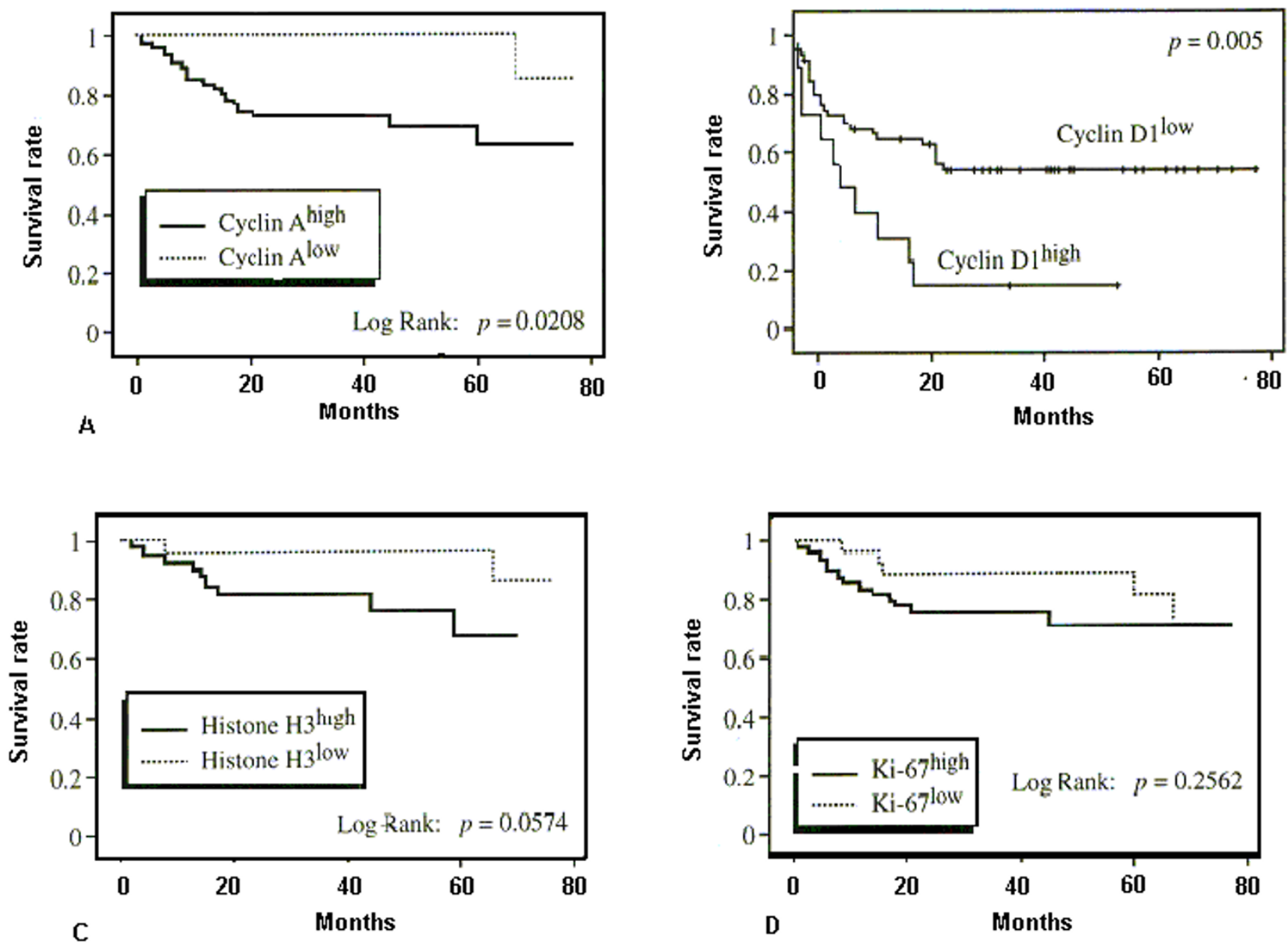

Figure 5

Kaplan-Meier survival curves for colorectal carcinoma. Overall survival is significantly lower in patients with (a) cyclin A and (b) cyclin DI overexpression. Patients with high SI for histone H3 mRNA have poorer prognosis but this was not statistically significant (c). No significant difference was present between patients with high Ki-67 SI and those with low Ki-67 SI (d).

ate regression analysis revealed that lymph node metastasis, cyclin A and cyclin D1 overexpression were independent negative prognostic factors after adjustment for the depth of tumor invasion, age and sex of the patient (Table 4).

\section{Discussion}

The proliferative activity of CRC cells has been investigated in several studies either by immunohistochemical determination of cell proliferation index using antibodies to some types of cyclins or by flowcytometric determination of the SPF of the cell cycle [8]. Although Leach et al. [17] did not find cyclin D1 gene amplification in a panel of 47 CRC cell lines; its protein was overexpressed in about $30 \%$ of CRC cases that were included in the studies of Bartakova et al. [6] and Arber et al. [18]. In the former study [6]cyclin D1 was aberrantly accumulated in a significant subset of human CRC cases and the cell lines derived from these cases were dependent on cyclin in their cell cycle progression. In the second study [18], overexpression of cyclin D1 was detected in $30 \%$ of adenomatous polyps indicating that overexpression is a relatively early event in colon carcinogenesis which is possibly responsible for the pathological changes in the mucosa preceding neoplastic transformation. More recently, Holland et al. [19], Pasz-Walczak et al. [20] and Utsunomiya et al. [21] reported up-regulation of cyclin D1 in 58.7\%, 100\% and $43 \%$ of their studied cases respectively. 
Table 4: Multivariate analysis ofthe relationship between survival and thetested markers

\begin{tabular}{|c|c|c|c|}
\hline PredictiveVariables & $H R$ & $\mathrm{Cl}$ & $P$ \\
\hline Cyclin DI & 10.864 & $1.055-86.250$ & $0.03^{*}$ \\
\hline (baseline < 6.1) & - & - & - \\
\hline Cyclin A & 13.886 & $1.012-190.579$ & $0.0490 *$ \\
\hline (baseline $<10.5$ ) & - & - & - \\
\hline $\begin{array}{l}\text { Positive Lymph node } \\
\text { metastasis }\end{array}$ & 3.921 & $1.057-14.472$ & $0.0410^{*}$ \\
\hline Stage IV & 3.411 & $1.048-12.083$ & $0.03^{*}$ \\
\hline \multicolumn{4}{|l|}{ Depth of invasion } \\
\hline $\mathrm{T} 3, \mathrm{~T} 4$ & 5.408 & $0.449-65.080$ & 0.1836 \\
\hline \multicolumn{4}{|l|}{ Age (years) } \\
\hline$\geq 50$ & 1.996 & $0.678-5.878$ & 0.2310 \\
\hline Sex & 0.910 & $0.315-2.358$ & 0.8453 \\
\hline
\end{tabular}

p. value $<0.05$ (significant)

HR: Hazard Ratio

Cl: $95 \%$ confidence Interval

In the present study, up-regulation of cyclin D1 was detected in $68.3 \%$ of the cases. The SI was significantly higher in carcinomas than in normal colorectal mucosa and in poorly-differentiated adenocarcinomas it was approximately twice that of other histological types. Amplification and/or overexpression of cyclin D1 significantly correlated with deeply invasive tumors and positive lymph node metastasis. Our results in this regards are consistent with previous studies $[8,22]$. In 2001, Holland et al. [19]. demonstrated that deregulation of cyclin D1 and p21 waf proteins are important in colorectal tumorigenesis and have implications for patient prognosis. Similarly McKay et al. [23] found that cyclin D1 was the only protein in their panel (cyclin D1, p53,p16, Rb-1, PCNA and p27) that correlated with improved outcome in CRC patients. However, few studies failed to detect any correlation between cyclin D1 overexpression and the clinicopathological factors in CRC $[6,18]$. This controversy in results could partially be explained by the difference in the sampling of studied cases. The present study included 24 cases of poorly differentiated adenocarcinoma, which is not common in other studies of CRC in western countries. This was possible because the majority of CRC cases diagnosed in Egypt are of high histological grade [3]. The correlation between cyclin D1 overexpression and the high histological grade was also reported in other tumor types including non-small cell lung carcinomas [24] and squamous cell carcinomas of the larynx [16]. Another possible explanation for the observed controversy in the results of different studies is the detection method used.

In the present work, overexpression of cyclin D1 was more common than gene amplification of the PRAD-1/cyclin D1 gene with a $63.6 \%$ concordance. This was similarly reported by Bartakova et al. [6] who mentioned that there is a subset of CRC cases in which cyclin D1 is overexpressed without PRAD-1/cyclin D1 gene amplification. Consistent with this hypothesis are reports of elevated $c y c$ lin D1 mRNA levels and immunohistochemically detectable accumulation of the protein in over one third of breast cancer cases at a frequency significantly higher than that deduced from DNA amplification studies $[9,25]$. These data imply that mechanisms other than gene amplification can also lead to deregulation and accumulation of cyclin D1 in solid tumors.

So far, several studies were done to reveal the prognostic significance of cyclin D1 overexpression in various carcinomas, including CRC [22]. However, these studies yielded conflicting results which could be attributed to organ heterogeneity. In our study, patients with tumors that exhibited cyclin D1 overexpression tended to have poor prognosis.

It was reported that, patients with cyclin A positive carcinomas had significantly shorter median survival times. Handa et al. [8] were able to detect $c y c l i n$ A overexpression in $77 \%$ of their CRC cases. They also demonstrated that, cylcin A could be used as a prognostic factor of CRC. More recently, Habermann et al. [26] studied cases of ulcerative colitis with and without an associated adenocarcinoma for the presence of cyclin A overexpression. They found that, cyclin A overexpression was higher in cases of ulcerative colitis with adenocarcinomas than in those without adenocarcinomas. Consequently, they concluded that, cyclin A could be used for monitoring ulcerative colitis patients and for the early detection of an emerging carcinoma in this high risk group of patients.

In our study, cyclin $A$ was detected in $80 \%$ of the patients and Cox regression analysis showed that it could be used as a prognostic marker in CRC in addition to cyclin D1.

It would have been useful if we assessed the expression level of cyclin $A$ by another technique (DNA amplification). This would have added more information regarding the gene status on one hand and confirmed the results of IHC on the other hand. Unfortunately, this was not possible because in most of the cases included in the present work, the extracted DNA was not sufficient to study cyclin amplification after the assessment of cyclin D1.

In 1996, Nagao et al. [11] reported that histone H3 labeling index significantly correlated with ki-67 immunostaining and was high in poorly differentiated human hepatocellular carcinoma. This was similarly reported in the present work since we found a significant correlation between the SI of histone $\mathrm{H3}$ and Ki-67. However, no 
statistically significant correlation was found between histone H3 SI and any of the studied clinicopathological factors.

Although $\mathrm{Ki}-67$ immunostaining reflects the proliferative activity of CRC, it has not been recognized as a significant prognostic factor in this type of tumors $[27,28]$. However, Suzuki at al. [29] found a significant correlation between Ki-67 labeling index and local invasion of CRC. In the present study there was a significant relationship between the SI of Ki-67, tumor size and grade. However, KaplanMeier survival curves showed no significant difference in survival rates between patients with- and without overexpression of $\mathrm{Ki}-67$.

\section{Conclusions}

Our results demonstrate that cyclin D1, cyclin A, histone H3 and $\mathrm{Ki}-67$ are overexpressed in a subset of CRC, however only cyclin D1 and cyclin A overexpression correlates with poor differentiation and tumor progression. This indicates the superiority of cyclin A and cyclin D1 as indicators of poor prognosis compared to $\mathrm{Ki}-67$ and histone $\mathrm{H} 3$ mRNA in CRC. Cyclin A and D1 could therefore be considered significant, independent prognostic factors in CRC patients. These findings are especially important in stage II patients since $25-30 \%$ of those patients have poor prognosis in spite of being node-negative. However, the standard clinicopathologic prognostic factors can not identify this subset accurately and therefore; there is a great demand for more accurate, individually-based, biological prognostic parameters that help in detecting this high risk group of patients who can benefit from an adjuvant therapy. If the findings of the present study are confirmed in a larger study, evaluation of cyclin $A$ and D1 may be applicable to clinical management of CRC, allowing the identification of patients with poor prognosis.

\section{Competing interests}

The author(s) declare that they have no competing interests.

$$
\begin{aligned}
& \text { List of abbreviations } \\
& \text { CRC - Colorectal cancer } \\
& \text { OS - overall survival } \\
& \text { SI - staining index } \\
& \text { SPF - S phase fraction } \\
& \text { ISH - in situ hybridization } \\
& \mathrm{m} \text { - muscularis mucosa } \\
& \text { sm - invasion of the sub mucosa }
\end{aligned}
$$

\section{Authors' contributions}

BA and ZA-R carried out the molecular genetic studies, designed, coordinated the study and drafted the manuscript. BA and El-HS carried out all the histopathological and immunohistochemical studies. El-SA participated in molecular genetic studies and drafted the manuscript. MM coordinated the study. El-SM carried out all the patient clinical data. All authors read and approved the final manuscript

\section{References}

I. Jiang GL, Huang S: Adenovirus expressing RIZI in tumor suppressor gene therapy of microsatellite unstable colorectal cancers. Cancer Res 200 I, 61: 1796-1798.

2. Soliman AS, Bondy ML, Levin B, Hamza MR, Ismail K, Ismail S, Hammam HM, El-Hattab O, Kamal SM, Soliman AG, Dorgham LA, McPherson RS, Beasley RP: Colorectal cancer in Egyptian patients under 40 years of age. Int J Cancer 1997, 71:26-30.

3. Soliman AS, Bondy ML, Guan Y, El-Badawy S, Mokhtar N, Bayomi S, Raouf AA, Ismail S, McPherson RS, Abdel-Hakim TF, Beasley PR, Levin $B$, Wei $Q$ : Reduced expression of mismatch repair genes in colorectal cancer patients in Egypt. Int J Oncol 1998, 12:1315-1319.

4. Cordon-Cardo C: Mutations of cell cycle regulators. Biological and clinical implications for human neoplasia. Am J pathol 1995 , 147:545-560.

5. Hunter T, Pines J: Cyclins and cancer. II. Cyclin D and CDK inhibitors come of age. Cell 1994, 79:573-528.

6. Bartkova J, Lukas J, Strauss M, Bartek J: The PRAD-I/cyclin DI oncogene product accumulates aberrantly in a subset of CRCs. Int J Cancer 1994, 58:568-573.

7. Motokura T, Arnold A: Cyclins and oncogenesis. Biochim Biophys Acta 1993, II55:63-78.

8. Handa K, Yamakawa M, Takeda H, Kimura S, Takahashi T: Expression of the cell cycle markers in colorectal carcinoma: Superiority of cyclin A as an indicator of poor prognosis. Int J cancer 1999, 84:225-233.

9. Gillett C, Fantl V, Smith R, Fisher C, Bartek J, Dickson C, Barnes D, Peters G: Amplification and overexpression of cyclin DI in breast cancer detected by immunohistochemical staining. Cancer Res 1994, 54:1812-1817.

10. Gown AM, Jiang Jj, Matles H, Skelly M, Goodpaster T, Cass L, Reshatof M, Spaulding D, Coltrera DM: Validation of the S-phase specificity of histone (H3) in situ hybridization in normal and malignant cells. J Histochem Cytochem 1996, 44:221-226.

II. Nagao T, Ishida Y, Kondo Y: Determination of S-phase cells by in situ hybridization for histone H3 mRNA in hepatocellular carcinoma: correlation with histological grade and other cell proliferative markers. Mod Pathol 1996, 9:99-104.

12. Chou MY, Chang AL, McBride J, Donoff B, Gallagher GT, Wong DT: $A$ rapid method to determine proliferation patterns of normal and malignant tissues by $\mathbf{H} 3$ mRNA in situ hybridization. Am J Pathol 1990, 136:729-733.

13. Sobin LH, Wittekind C: TNM classification of malignant tumors. 5th edition. John Wiley, New York; 1997.

14. King RJ, Coffer Al, Gilbert J, Lewis K, Nash R, Millis R, Raju S, Taylor RW: Histochemical studies with a monoclonal antibody raised against a partially purified soluble estradiol receptor preparation from human myometrium. Cancer Res 1985 , 45:5728-5733.

15. Slebos RJ, Boerrigter L, Evers SG, Wisman P, Mooi WJ, Rodenhuis S: $A$ rapid and simple procedure for the routine detection of ras point mutations in formalin-fixed, paraffin-embedded tissues. Diag Moln Path 1992, I:I36-141.

16. Jares P, Fernandez P, Campo E, Nadal A, Bosch F, Aiza G, Nayach I, Traserra J, Cardesa A: PRAD-I/cyclin DI gene amplification correlates with messenger RNA overexpression and tumor progression in human laryngeal carcinomas. Cancer Res 1994, 54:4813-4817.

17. Leach FS, Elledge SJ, Sherr CJ, Willson JK, Markowitz S, Kinzler KW, Vogelstein B: Amplification of cyclin genes in colorectal carcinomas. Cancer Res 1993, 53:1986-1989. 
18. Arber N, Hibshoosh H, Moss SF, Sutter T, Zhang Y, Begg M, Wang S, Weinstein IB, Holt PR: Increased expression of cyclin DI is an early event in multistage colorectal carcinogenesis. Gastroenterology 1996, I I 0:669-674.

19. Holland TA, Elder J, McCloud JM, Hall C, Deakin M, Fryer AA, Elder JB, Hoban PR: Subcellular localization of cyclin DI protein in colorectal tumors is associated with p2I (WAFI/CIPI) expression and correlates with patient survival. Int J Cancer 200I, 95(5):302-306.

20. Pasz-Walczak G, Kordek R, faflik M: P2I(WAFI) expression in colorectal cancer: correlation with p53 and cyclin D I expression, clinicopathological parameters and prognosis. Pathol Res Pract 200I, 197(10):683-689.

21. Utsunomiya T, Doki Y, Takemoto H, Shiozaki H, Yano M, Sekimoto M, Tamura S, Yasuda T, Fujiwara Y, Monden M: Correlation of beta-catenin and cyclin DI expression in colon cancers. Oncology 200I, 6 I (3):226-233.

22. Maeda K, Chung YS, Kang SM, Ogawa M, Onoda N, Nakata B, Nishiguchi $Y$, Ikehara T, Okuno M, Sowa M: Overexpression of cyclin DI and p53 is associated with disease recurrence in colorectal adenocarcinoma. Int JCancer 1997, 74:3 I0-3I5.

23. McKay JA, Douglas JJ, Ross VG, Curran S, Loane JF, Ahmed FY, Cassidy J, McLeod HL, Murray GI: Analysis of key cell cycle checkpoint proteins in colorectal tumors. J Pathol 2002, 196:386-393.

24. Mate JL, Ariza A, Aracil C, Lopez D, Isamat M, Perez-Piteira J, NavasPalacios Jj: Cyclin DI overexpression in non-small cell lung carcinoma: correlation with Ki-67 labeling index and poor cytoplasmic differentiation. J Pathol 1996, I 80:395-399.

25. Buckley MF, Sweeney KJ, Hamilton JA, Sini RL, Manning DL, Nicholson RI, DeFazio A, Watts CK, Musgrove EA, Sutherland RL: Expression and amplification of cyclin genes in human breast cancer. Oncogene 1993, 8:2127-2133.

26. Habermann J, Lenander C, Roblick UJ, Kruger S, Ludwig D, Alaiya A, Freitag S, Dumbgen L, Bruch HP, Stange E, Salo S, Tryggvason K, Auer $\mathrm{G}$, Schimmelpenning $\mathrm{H}$ : Ulcerative colitis and colorectal carcinoma: DNA profile, laminin-5 gamma 2 chain and cyclin A expression as early markers for risk assessment. Scand J Gastroenterol 200I, 36:75I-758.

27. Kubota Y, Petras RE, Easley KA, Bauer TW, Tubbe RR, Fazio VW: Ki67-determined growth fraction versus standard staging and grading parameters in colorectal carcinoma. A multivariate analysis. Cancer 1992, 70:2602-2609.

28. Shain AA, Ro JY, Brown RW, Ordonez NG, Cleary KR, El-Naggar AK Wilson P, Ayala AG: Assessment of Ki-67-derived tumor proliferative activity in colorectal adenocarcinomas. Mod Pathol 1994, 7:17-22.

29. Suzuki H, Matsumoto $K$, Terabe M: Ki-67 antibody labeling index in colorectal carcinoma. J clin Gastroenterol 1992, 15:3 17-320.

\section{Pre-publication history}

The pre-publication history for this paper can be accessed here:

http://www.biomedcentral.com/1471-230X/4/22/pre

pub

Publish with Bio Med Central and every
scientist can read your work free of charge
"BioMed Central will be the most significant development for
disseminating the results of biomedical research in our lifetime. "
Sir Paul Nurse, Cancer Research UK
Your research papers will be:
- available free of charge to the entire biomedical community
- peer reviewed and published immediately upon acceptance
- cited in PubMed and archived on PubMed Central
- yours - you keep the copyright
Submit your manuscript here:
http://www.biomedcentral.com/info/publishing_adv.asp

